\title{
Evacuation of the ICU
}

\section{Care of the Critically Ill and Injured During Pandemics and Disasters: CHEST Consensus Statement}

\author{
Mary A. King, MD, MPH, FCCP; Alexander S. Niven, MD, FCCP; William Beninati, MD; Ray Fang, MD; Sharon Einav, MD; \\ Lewis Rubinson, MD, PhD; Niranjan Kissoon, MBBS, FRCPC; Asha V. Devereaux, MD, MPH, FCCP; \\ Michael D. Christian, MD, FRCPC, FCCP; and Colin K. Grissom, MD, FCCP; on behalf of the Task Force for Mass Critical Care
}

BACKGROUND: Despite the high risk for patient harm during unanticipated ICU evacuations, critical care providers receive little to no training on how to perform safe and effective ICU evacuations. We reviewed the pertinent published literature and offer suggestions for the critical care provider regarding ICU evacuation. The suggestions in this article are important for all who are involved in pandemics or disasters with multiple critically ill or injured patients, including front-line clinicians, hospital administrators, and public health or government officials.

METHODS: The Evacuation and Mobilization topic panel used the American College of Chest Physicians (CHEST) Guidelines Oversight Committee's methodology to develop seven key questions for which specific literature searches were conducted to identify studies upon which evidence-based recommendations could be made. No studies of sufficient quality were identified. Therefore, the panel developed expert opinion-based suggestions using a modified Delphi process.

RESULTS: Based on current best evidence, we provide 13 suggestions outlining a systematic approach to prepare for and execute an effective ICU evacuation during a disaster. Interhospital and intrahospital collaboration and functional ICU communication are critical for success. Pre-event planning and preparation are required for a no-notice evacuation. A Critical Care Team Leader must be designated within the Hospital Incident Command System. A threestage ICU Evacuation Timeline, including (1) no immediate threat, (2) evacuation threat, and (3) evacuation implementation, should be used. Detailed suggestions on ICU evacuation, including regional planning, evacuation drills, patient transport preparation and equipment, patient prioritization and distribution for evacuation, patient information and tracking, and federal and international evacuation assistance systems, are also provided.

CONCLUSIONS: Successful ICU evacuation during a disaster requires active preparation, participation, communication, and leadership by critical care providers. Critical care providers have a professional obligation to become better educated, prepared, and engaged with the processes of ICU evacuation to provide a safe continuum of critical care during a disaster.

CHEST 2014; 146(4_Suppl):e44S-e60S

ABBREVIATIONS: CCTL $=$ Critical Care Team Leader; ECMO $=$ extracorporeal membrane oxygenation; $\mathrm{EOC}=$ emergency operations center; NDMS = National Disaster Medical System

Revision accepted May 1, 2014; originally published Online First August 21, 2014.

AFFILIATIONS: From University of Washington (Dr King), Harborview Medical Center, Seattle, WA; Madigan Army Medical Center (Dr Niven), Uniformed Services University of Health Sciences, Tacoma, WA; Intermountain Tele-Critical Care (Dr Beninati), University of Utah School of
Medicine, Salt Lake City, UT; University of Maryland Medical Center (Dr Fang), Baltimore, MD; Shaare Zedek Medical Center (Dr Einav), Hebrew University Faculty of Medicine, Jerusalem, Israel; R. Adams Cowley Shock Trauma Center (Dr Rubinson), University of Maryland School of Medicine, Baltimore, MD; BC Children's Hospital and Sunny Hill Health Centre (Dr Kissoon), University of British Columbia, 


\section{Summary of Suggestions}

\section{Form Hospital and Transport Agreements}

1a. We suggest local and regional mutual-aid agreements should be established with other appropriately staffed and resourced hospitals to redistribute critically ill and injured patients from an evacuating hospital(s), and these agreements should be integrated within the framework of disaster preparedness plans.

1b. We suggest creation of predisaster formal agreements between hospitals and transport agencies or between Health Coalitions or Regional Health Authorities and transport agencies for air or ground transport of critically ill patients during a disaster.

\section{Prepare for and Simulate Critical Care Evacuation}

2a. We suggest staffing requirements within disaster plans should take into account the staffing resources necessary for desired surge capability to both safely move patients and to provide continuous care for patients remaining in the ICU.

$2 b$. We suggest developing a detailed vertical evacuation plan using stairs when applicable for critically ill and injured patients.

2c. We suggest hospital exercises should simulate a mass critical care event and include vertical evacuation when applicable that evaluates (1) patient movement using specialized evacuation equipment and (2) the ability to maintain effective respiratory and hemodynamic support while moving down stairs.

\section{Prepare for and Simulate Critical Care Transport}

3a. We suggest specialized care is resource intensive, and specialized ground and aeromedical teams may be required to ensure appropriate initial and ongoing care prior to and during evacuation. 3b. We suggest preidentifying unique transport resources that are required for movement of specific populations, such as critically ill neonates, children, and technology-dependent patients, at a regional level. This information can then be used in real time to match allocated resources to patients.

$3 \mathrm{c}$. We suggest conducting detailed and realistic exercises that require ICU evacuation with local and regional ground and air transport agencies.

\section{Designate a Critical Care Team Leader}

4a. We suggest the Incident Management System at the evacuating ICU hospital should support early and frequent communication between Incident Command and a designated Critical Care Team Leader (CCTL) during an impending evacuation to provide close coordination and support of ICU evacuation preparations.

4b. We suggest the CCTL coordinating the critical care evacuation should be responsible for (1) categorizing ICU patients by ICU resource requirement and (2) communicating these ICU patient resource requirements with the Hospital Incident Command and to any Regional or National Emergency Command Center supporting hospital evacuation.

4c. We suggest when preparing for and during an ICU evacuation, a primary role of the CCTL should be to categorize each candidate ICU patient evacuee by (1) ICU resources required and (2) skill set of transport staff required.

4d. We suggest CCTLs and staff should receive special training, education, and practice on patient categorization and transport requirements.

4e. Expert providers from evacuation teams and outside facilities, when possible through face-toface communication on site, can help ensure
Vancouver, BC, Canada; Sharp Hospital (Dr Devereaux), Coronado, CA; Royal Canadian Medical Service (Dr Christian), Canadian Armed Forces and Mount Sinai Hospital, Toronto, ON, Canada; and Intermountain Medical Center (Dr Grissom), University of Utah, Salt Lake City, UT. FUNDING/SUPPORT: This publication was supported by the Cooperative Agreement Number 1U90TP00591-01 from the Centers of Disease Control and Prevention, and through a research sub award agreement through the Department of Health and Human Services [Grant 1 HFPEP070013-01-00] from the Office of Preparedness of Emergency Operations. In addition, this publication was supported by a grant from the University of California-Davis

COI grids reflecting the conflicts of interest that were current as of the date of the conference and voting are posted in the online supplementary materials.
DISCLAIMER: American College of Chest Physicians guidelines and consensus statements are intended for general information only, are not medical advice, and do not replace professional care and physician advice, which always should be sought for any medical condition. The complete disclaimer for this consensus statement can be accessed at http://dx.doi.org/10.1378/chest.1464S1

CORRESPONDENCE To: Mary A. King, MD, MPH, Pediatric Trauma Intensive Care Unit, Harborview Medical Center, 325 9th Ave, Box 359774, Seattle, WA 98104; e-mail: maryking@uw.edu

(c) 2014 AMERICAN COLLEGE OF CHEST PHYSICIANS. Reproduction of this article is prohibited without written permission from the American College of Chest Physicians. See online for more details. DOI: $10.1378 /$ chest.14-0735 
appropriate transport planning and distribution based on available resources during transport and in receiving facilities.

\section{Initiate Pre-Event ICU Evacuation Plan}

5a. If pre-event hospital evacuation of critically ill patients might be required, then we suggest planning for patient evacuation or shelter in place using an Incident Command System should begin as early as possible. Possible strategies include shelter in place, partial evacuation, or early evacuation, depending on the circumstances.

5b. We suggest Hospital Incident Command during a threatened hospital evacuation should have a clear and direct mechanism for communication with local governing bodies that control the timing and issuance of regional evacuation orders. To prevent obstruction of ground medical transport during hospital evacuation, coordination with local government regarding timing of recommendations for evacuation of the general population may be required. Efficient ground medical transport of patients during a hospital evacuation may be facilitated by providing a time period for hospital evacuation prior to recommendations for evacuation of the general population.

\section{Requesting Assistance for Evacuation}

6a. We suggest during a disaster or pandemic that overwhelms local and regional resources and requires large-scale hospital evacuations assistance, from national and/or international government medical support and evacuation agencies should be requested.

6b. We suggest the CCTL should be aware of the process for requesting evacuation assistance and the resources available at a regional and national level.

\section{Ensure Adequate Power and Transport Ventilation Equipment}

7a. We suggest surge ventilators with flexible electrical power and oxygen requirements should be available to support patients with respiratory failure that can maintain function while either (1) sheltering in place or (2) evacuating to an outside facility. These ventilators should be portable, run on alternating current power with battery backup, and have the ability to run on low-flow oxygen without a high-pressure gas source. Surge ventilators may be of limited capability but should be able to ventilate and oxygenate patients with acute lung injury or ARDS as well as airflow obstruction. This requires capability to deliver a high minute ventilation, high flow, and high positive end-expiratory pressure. They should be safe (disconnect alarm) and relatively easy for staff to operate.

7b. We suggest availability of adequate portable energy and medical gas flexible ventilators that can provide accurate small tidal volumes or pressure limits for the premature and neonatal patients expected at designated hospitals (for instance pediatric centers or hospitals with a neonatal ICU). Special consideration should be given to creating a standard, quickly accessible regional stockpile of mechanical ventilators for evacuation of neonatal patients as it may not be feasible for some nonpediatric centers to have adequate numbers of portable energy and gas flexible neonatal ventilators.

\section{Prioritizing Critical Care Patients for Evacuation}

8. We suggest evacuation order and identification of appropriate facility should be based on the following factors:

8a. In a time-limited evacuation, less critical patients can be evacuated faster and with fewer resources per patient and, thus, may be moved first in order to evacuate the most patients in the fastest time.

$8 b$. When there is adequate time for evacuation, then more critically ill patients may be moved first and in parallel with less ill patients. Similar acuity patients often use similar transport resources and strain the same group of sending staff members. Thus, moving both the less critical and more critical patients simultaneously in parallel, as compared with sequentially in series (when there is adequate time to evacuate the entire hospital), may decrease the overall time to evacuation.

8c. In some situations, moving groups of similar-type patients to a single hospital entity may enable the sending hospital to provide staff to a single location to facilitate continuity of care and allow receiving hospitals to preplan to surge for specific types of patients and cluster disaster resources.

8d. The most critically ill patients dependent on mechanical devices for life support may, in some conditions, be safely cared for with a shelter-in-place strategy if it is deemed the risk of evacuation is too high.

\section{Critical Care Patient Distribution}

9a. We suggest during isolated, small, or pre-event ICU evacuations, CCTLs should coordinate with 
Hospital Incident Command and identify receiving hospitals for patient evacuation via the usual practice of provider-to-provider communication.

$9 \mathrm{~b}$. We suggest during multiple-facility, large, or late ICU evacuations, the usual provider-toprovider system of communication for identification of receiving facilities should be augmented by other Regional or National Incident Management Systems.

9b.i. Every hospital should be specifically affiliated with (and drill evacuation with) a Regional or National Command Center for such events. Regional or National Command Centers may need to assume responsibility for designation of the receiving facilities for their patients.

9b.ii. We suggest when a Regional or National Emergency Command Center assumes responsibility for patient distribution, they should be responsible for identifying receiving facilities that match ICU patient resource requirements.

9b.iii. We suggest the Regional or National Emergency Command Center should enlist assistance of regional specialist experts to assist in the above matching process for distribution of patients requiring highly specialized care among receiving centers.

9c. We suggest assignment of transportation resources and lines of critical care patient evacuation should follow common existing referral patterns provided receiving facilities retain adequate capacity to care for these patients.

9d. We suggest patients who require advanced specialty care should be directed to high-volume centers and distribution take into account the capacity and resources required to provide ongoing care to these patients.

\section{Preparing the Critical Care Patient for Evacuation}

10a. We suggest standardized preparation of critically ill patients should be performed prior to hospital-tohospital transfer, including initial stabilization, diagnostic procedures, damage control procedures, and medical interventions, to address anticipated physiologic changes during transport.

10b. We suggest the transport team should provide the equipment used for transport to ensure compatibility and familiarity during transport and retain important resources at the source institution for ongoing care of the remaining patients.

10c. We suggest evacuation planning and coordination should include the provision of additional expert providers, staff, and equipment to assist in the ongoing provision of care in situations where patient volume, acuity, or nature of illness or injury exceeds the capabilities of the CCTL and staff.

10d. We suggest utilizing a staging area for patients prepared and awaiting transport. This area should ideally be located near the point of embarkation and be staffed by medical personnel with training and experience in critical care evacuation. These personnel should be prepared to provide triage and perform ongoing medical care interventions prior to transport. The area should have the capability for additional surgical and medical stabilization pretransport if necessary.

\section{Sending Critical Care Patient Information With Patient}

11a. We suggest electronic transfer of patient information to the receiving hospital is optimal because a complete medical record can be included. Electronic transfer may be through an intranet or by copying patient information onto a USB flash memory drive or compact disk and transferring the information with the patient (see the "Business and Continuity of Operations" article in this consensus statement).

$11 \mathrm{~b}$. We suggest a paper medical record be required to travel with the patient because there may be no ability to send an electronic copy of the medical record, or the receiving facility may not be able to read the electronic format of the medical record. A backup paper system may require (a) a printed copy of the electronic medical record or (b) a handwritten patient identification on a standardized patient tracking form. Any paper system should include basic patient identification, problem lists, and medications on forms that travel with the patient.

\section{Transporting Critical Care Patients to Receiving Hospitals}

12a. We suggest transportation methods should prioritize moving the greatest number of patients as rapidly and safely as possible to locations with adequate capacity and expertise where definitive care can be provided. 
12b. We suggest local evacuation of highest acuity patients to hospitals with additional capacity by ground or rotary transport may be most appropriate to minimize risk and reduce ongoing critical care demands at the incident facility.

$12 \mathrm{c}$. We suggest alteration in the usual standards for modes of transport may be required during a disaster where transport resources are overwhelmed and evacuation and transport of critically ill patients to a receiving hospital ICU is required.

\section{Tracking Critical Care Patients and Equipment}

13a. We suggest tracking of patients should commence in the sending clinical unit, continue to the point of embarkation, and if possible, continue to the destination facility. Tracking of the patient and equipment should commence prior to being loaded onto the transportation. Minimum data sets for tracking should include the patient first and last name, date of birth, medical record number or tracking number or triage number, time leaving facility, transportation company name and transport vehicle number, and expected destination and next of kin.

13b. We suggest both the evacuating and receiving hospitals should track patients and equipment.

13c. We suggest tracking systems may be electronic or paper. In the event of complete power failure, however, a redundant paper system for tracking of patients and equipment should be performed by both sending and receiving hospitals, with communications provided to the sending hospital and/or a centralized coordinating center to confirm receipt of the patients.

13d. We suggest evacuation drills should test tracking of patients and equipment both by electronic and paper systems.

\section{Introduction}

Recent disasters have revealed that critical care units, whether small community hospital ICUs or quaternary academic specialized ICUs, may be required to evacuate their patients with limited pre-event notice. Critical care patients are especially vulnerable during evacuation because they are medically fragile and require special equipment and expertise. The typical day-to-day transfer system of critically ill patients with direct provider-to-provider discussion and transfer paperwork can easily fail during a disaster when rapid evacuation of multiple patients is required and power, communication, and transportation are compromised. Timely, effective, and safe evacuation of critical care patients is essential in a disaster, but many critical care providers receive little to no training in evacuation preparedness and implementation. Disaster planners and leaders also often have little critical care expertise and yet, are frequently responsible for ICU evacuation when an actual event occurs.

Typical emergency medical service providers lack the skill set required to transfer complex, critically ill patients once intensive care interventions are initiated; thus, they are unfamiliar with or underequipped for the numerous care requirements and considerations in these patients. Critical care transport providers are familiar with the critical care patient and interventions, but these providers are in limited supply. Evacuation of quaternary academic centers is especially fraught with problems because they are typically receiving facilities; they have little practice or systems in place to serve as sending facilities. Documentation systems for simultaneously moving multiple, very complex patients from an ICU setting are not established, and direct physician-to-physician and nurse-to-nurse communication may no longer be possible during transfer of care. The ability to generate detailed transfer summaries and to copy records and images may be limited by infrastructure damage and inadequate time.

This ICU evacuation scenario, evident during Hurricanes Katrina, Gustav, Ike, and Sandy, highlights the need for critical care providers to learn, plan, and train in all aspects of an ICU evacuation to ensure safe patient transfer. ICU evacuation was not included as a central topic in the prior American College of Chest Physicians (CHEST) consensus statement; this consensus development process and literature search, therefore, was created de novo. The topic panel elected to review the literature and present the data from the perspective of the ICU medical director faced with an ICU Evacuation Timeline (Fig 1).

The suggestions in this article are important for all involved in a disaster or pandemic with critically ill patients, including front-line clinicians, hospital administrators, and public health or government officials. Although it is important for all providers to be familiar with critical care evacuation, Table 1 provides an overview of the suggestions of most interest to each group. 


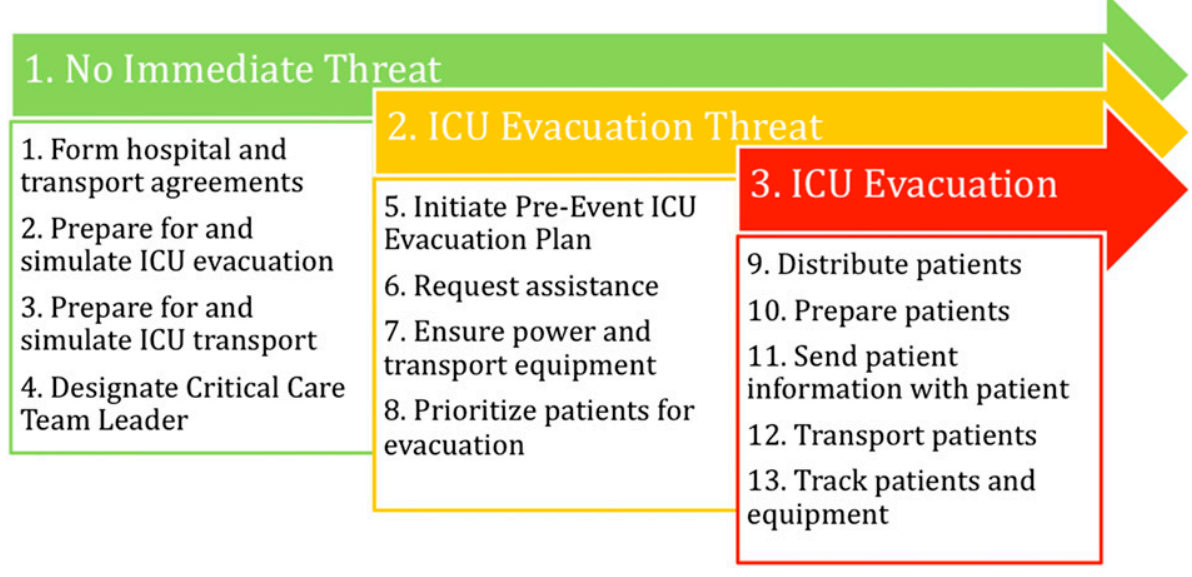

Figure 1 - ICU Evacuation Timeline. We recommend this timeline as a general approach for ICU evacuation preparation and performance. The suggestions included in this article correspond by number to these steps. Similar to the three tiers for Crisis Standards of Care (conventional, contingency, and crisis), ICU evacuation comprises three stages: (1) no immediate threat, (2) ICU evacuation threat, and (3) ICU evacuation. Note that the ICU Evacuation Timeline is a continuum, with overlap between stages because many of the later-stage steps are actually initiated at an earlier stage (eg, preparation of patient information).

\begin{abstract}
Materials and Methods
The Evacuation and Mobilization topic panel followed the CHEST Guidelines Oversight Committee's methodology to develop suggestions (see the "Methodology" article by Ornelas et $\mathrm{al}^{1}$ in this consensus statement). The Evacuation and Mobilization topic panel developed seven key questions, and four literature searches were conducted to identify evidence on which to base suggestions, using the PubMed/ MEDLINE database (see e-Appendix 1 for a list of key questions and corresponding search terms and results). Searches were limited from 1980 to 2012. Inclusion criteria included English-language articles with a focus on patient evacuation (either in general or during a disaster),
\end{abstract}

emphasis on hospital-based care and considerations, specific disaster episodes, and critical care transportation experience or systems. Exclusion criteria included disaster articles without information on patient transport and evacuation or with an emphasis on prehospital care or care of chronic, stable populations requiring technology and ongoing medical care during disasters. A total of 139 of 519 articles were selected for critical review. Despite this exhaustive search of the literature, no studies of sufficient quality were identified upon which to make evidence-based recommendations. Therefore, the panel developed expert opinion-based suggestions using a modified Delphi process.

\section{Results}

\section{Form Hospital and Transport Agreements}

\section{1a. We suggest local and regional mutual-aid} agreements should be established with other appropriately staffed and resourced hospitals to redistribute critically ill and injured patients from an evacuating hospital(s), and these agreements should be integrated within the framework of disaster preparedness plans.

\section{1b. We suggest creation of predisaster formal agreements between hospitals and transport agencies or between Health Coalitions or Regional Health Authorities and transport agencies for air or ground transport of critically ill patients during a disaster.}

Critical care providers should participate in a hospital or region-wide process to identify risks and vulnerabilities and create a written plan for evacuation within and from their hospital. ${ }^{2}$ Although most guidelines focus on a centralized command system to govern evacuation decisions and movement, flexibility and redundancy should be retained in decision-making. Small-scale events may allow sufficient planning time to use normal transfer patterns and practices; major large-scale events or significant infrastructure damage may require off-site or regional coordination. ${ }^{3}$ Important considerations in planning agreements are (1) identification of regional critical care capacity and specialty resources ${ }^{4} ;(2)$ prior designation and centralized, coordinated deployment of ground and air transport with critical care capabilities ${ }^{5,6}$; (3) stereotyped evacuation patterns based on volume and severity; and (4) special needs of critically ill patients. ${ }^{7-9}$ One advantage of creating these mutual-aid agreements is the identification of patient populations that would be best served at specific preidentified facilities, similar to the New York City schema achieved with preidentifying burn disaster receiving hospitals. ${ }^{10}$ Mutual-aid agreements often are complex to develop and negotiate; therefore, it is important that these are secured well in advance of a disaster or pandemic rather than attempting to arrange them just before or during an event.

A large number of disaster case reports indicate a lack of preidentified recipient hospitals, specifically during 9/11, ${ }^{11}$ Hurricane Katrina, ${ }^{12,13}$ the Fukushima Nuclear Plant crisis, ${ }^{14}$ and Hurricane Sandy. ${ }^{15}$ Few hospitals and regional health-care coalitions have created mutual-aid agreements for this purpose. ${ }^{16,17}$ Even fewer hospitals or coalitions, however, have used such agreements; when they have, financial compensation for patient transfer 
TABLE 1 ] Primary Target Audiences for Suggestions

\begin{tabular}{|c|c|c|c|}
\hline Suggestion & Clinicians & $\begin{array}{c}\text { Hospital } \\
\text { Administrators }\end{array}$ & $\begin{array}{c}\text { Public } \\
\text { Health and } \\
\text { Government }\end{array}$ \\
\hline $1 a$ & $\checkmark$ & $\checkmark$ & $\checkmark$ \\
\hline $1 b$ & $\checkmark$ & $\checkmark$ & $\checkmark$ \\
\hline $2 a$ & $\checkmark$ & $\checkmark$ & \\
\hline $2 b$ & $\checkmark$ & $\checkmark$ & \\
\hline $2 c$ & $\checkmark$ & $\checkmark$ & \\
\hline $3 a$ & $\checkmark$ & $\checkmark$ & \\
\hline $3 b$ & $\checkmark$ & $\checkmark$ & \\
\hline $3 c$ & $\checkmark$ & $\checkmark$ & \\
\hline $4 a$ & $\checkmark$ & $\checkmark$ & \\
\hline $4 b$ & $\checkmark$ & $\checkmark$ & \\
\hline $4 c$ & $\checkmark$ & $\checkmark$ & \\
\hline $4 d$ & $\checkmark$ & $\checkmark$ & \\
\hline $4 e$ & $\checkmark$ & $\checkmark$ & \\
\hline $5 a$ & $\checkmark$ & $\checkmark$ & $\checkmark$ \\
\hline $5 b$ & $\checkmark$ & $\checkmark$ & $\checkmark$ \\
\hline $6 a$ & $\checkmark$ & $\checkmark$ & $\checkmark$ \\
\hline $6 b$ & $\checkmark$ & $\checkmark$ & $\checkmark$ \\
\hline $7 a$ & $\checkmark$ & $\checkmark$ & \\
\hline $7 b$ & $\checkmark$ & $\checkmark$ & \\
\hline $8 a$ & $\checkmark$ & $\checkmark$ & $\checkmark$ \\
\hline $8 b$ & $\checkmark$ & $\checkmark$ & $\checkmark$ \\
\hline $8 c$ & $\checkmark$ & $\checkmark$ & $\checkmark$ \\
\hline $8 d$ & $\checkmark$ & $\checkmark$ & $\checkmark$ \\
\hline $9 a$ & $\checkmark$ & $\checkmark$ & $\checkmark$ \\
\hline $9 b$ & $\checkmark$ & $\checkmark$ & $\checkmark$ \\
\hline $\mathrm{i}$ & $\checkmark$ & $\checkmark$ & $\checkmark$ \\
\hline ii & $\checkmark$ & $\checkmark$ & $\checkmark$ \\
\hline $\mathrm{iii}$ & $\checkmark$ & $\checkmark$ & $\checkmark$ \\
\hline $9 c$ & $\checkmark$ & $\checkmark$ & $\checkmark$ \\
\hline $9 d$ & $\checkmark$ & $\checkmark$ & $\checkmark$ \\
\hline $10 a$ & $\checkmark$ & $\checkmark$ & \\
\hline $10 b$ & $\checkmark$ & $\checkmark$ & \\
\hline $10 \mathrm{c}$ & $\checkmark$ & $\checkmark$ & \\
\hline $10 d$ & $\checkmark$ & $\checkmark$ & \\
\hline $11 a$ & $\checkmark$ & $\checkmark$ & \\
\hline $11 \mathrm{~b}$ & $\checkmark$ & $\checkmark$ & \\
\hline $12 a$ & $\checkmark$ & $\checkmark$ & $\checkmark$ \\
\hline $12 b$ & $\checkmark$ & $\checkmark$ & $\checkmark$ \\
\hline $12 c$ & $\checkmark$ & $\checkmark$ & $\checkmark$ \\
\hline $13 a$ & $\checkmark$ & $\checkmark$ & \\
\hline $13 b$ & $\checkmark$ & $\checkmark$ & \\
\hline $13 c$ & $\checkmark$ & $\checkmark$ & \\
\hline $13 d$ & $\checkmark$ & $\checkmark$ & \\
\hline
\end{tabular}

and proper credentialing of outside providers have been cited as significant challenges. ${ }^{18}$ Hospitals and coalitions should consider defining the process of provider credentialing, repatriation, and payment for services rendered once a crisis resolves. ${ }^{18}$

Prepare for and Simulate Critical Care Evacuation

2a. We suggest staffing requirements within disaster plans should take into account the staffing resources necessary for desired surge capability to both safely move patients and to provide continuous care for patients remaining in the ICU.

$2 b$. We suggest developing a detailed vertical evacuation plan using stairs when applicable for critically ill and injured patients.

2c. We suggest hospital exercises should simulate a mass critical care event and include vertical evacuation when applicable that evaluates (1) patient movement using specialized evacuation equipment and (2) the ability to maintain effective respiratory and hemodynamic support while moving down stairs.

In US hospitals, disasters are due to (in order of decreasing frequency) fire, hazardous material events, hurricane damage, human threats, earthquakes, flooding, and utility failure. ${ }^{19}$ More than $50 \%$ of hospital evacuations are due to internal hospital events, but the most severe problems and largest scale hospital evacuations have been due to natural hazards. ${ }^{19}$ Hospitals are poorly prepared to deal with these events, ${ }^{20}$ and there are significant operational challenges to moving patients from hospital areas to the ground floor for evacuation ${ }^{21}$ or to makeshift landing zones on rooftops and in parking garages. ${ }^{13,22,23}$ Simulated vertical evacuations provide excellent examples of the challenges and technical considerations involved with this task ${ }^{21,24-26}$ (see e-Appendix 2 for an example ${ }^{27}$ ) Therefore, disaster plans that consider staffing requirements for safe and rapid vertical evacuation are important.

Prepare for and Simulate Critical Care Transport

3a. We suggest specialized care is resource intensive, and specialized ground and aeromedical teams may be required to ensure appropriate initial and ongoing care prior to and during evacuation.

$3 b$. We suggest preidentifying unique transport resources that are required for movement of specific 
populations, such as critically ill neonates, children, and technology-dependent patients, at a regional level. This information can then be used in real time to match allocated resources to patients.

$3 c$. We suggest conducting detailed and realistic exercises that require ICU evacuation with local and regional ground and air transport agencies.

Multiple reports have described the hazards of planning and conducting large-scale critical care movement at the time of a disaster. Such efforts have been marked by significant heroism but lack of resource coordination, resulting in frequent reductions in patient monitoring and supportive care, which create safety concerns. $13,14,16,22,28$ In overwhelming disasters, such resource limitation is likely inevitable, but without pre-event planning and preparedness, even small events can lead to patients being hurt due to poorly allocated resources. Successful evacuation examples and expert consensus consistently cite early use of an Incident Command System to evaluate, communicate, and coordinate health-care and evacuation requirements both within a hospital and between hospitals in a region, depending on the magnitude of the inciting event. 7,29

For health-care systems that do not use such coordinating systems as part of their daily routine, detailed planning and realistic drills that use likely disaster scenarios to test command and communication systems and that include the interaction of relevant hospital personnel should be undertaken. Preparation and transport of simulated patients using actual transport equipment increases the likelihood of successful individual performance and systemwide cooperation. ${ }^{10,24,30}$ Detailed recommendations and core competencies for training are published elsewhere. ${ }^{31,32}$ Common problem areas deserving additional focus include contingency plans when ICUs suffer significant infrastructure damage, ${ }^{3,19,20}$ timing of evacuation, ${ }^{2}$ evacuation methods (including vertical evacuation plans), ${ }^{21,24-26}$ patient distribution, and tracking.

The 9/11 disaster highlighted the paucity of pediatric medical resources compared with available adult services, ${ }^{11}$ and multiple accounts have detailed the inadequacy of disaster preparedness plans to address the needs of neonates. ${ }^{33,34}$ Patients with extensive burns, severe hypoxemic respiratory failure, and other advanced technology requirements for ongoing care (eg, intraaortic balloon pumps for temporizing cardiogenic shock, externalized ventricular drainage for a severe subarachnoid hemorrhage) require specialized evacuation considerations and care during transport. ${ }^{31,35-39}$
Centralized regional real-time tracking and communication are essential to match available facilities' resources to patients and minimize transportation duration and mishaps. ${ }^{7}$ Close coordination with specialty centers can minimize adverse outcomes during transport. ${ }^{36,40}$

\section{Designate a Critical Care Team Leader}

4a. We suggest the Incident Management System at the evacuating ICU hospital should support early and frequent communication between Incident Command and a designated Critical Care Team Leader (CCTL) during an impending evacuation to provide close coordination and support of ICU evacuation preparations.

4b. We suggest the CCTL coordinating the critical care evacuation should be responsible for (1) categorizing ICU patients by ICU resource requirement and (2) communicating these ICU patient resource requirements with the Hospital Incident Command and to any Regional or National Emergency Command Center supporting hospital evacuation.

4c. We suggest when preparing for and during an ICU evacuation, a primary role of the CCTL should be to categorize each candidate ICU patient evacuee by (1) ICU resources required and (2) skill set of transport staff required.

4d. We suggest CCTLs and staff should receive special training, education, and practice on patient categorization and transport requirements.

4e. Expert providers from evacuation teams and outside facilities, when possible through face-to-face communication on site, can help ensure appropriate transport planning and distribution based on available resources during transport and in receiving facilities.

Safe and timely ICU evacuation demands real-time knowledge of the quantity, severity, and resource intensity of multiple critically ill patients, often across multiple units, and the special equipment and transport needs they may require both during transport and at the receiving facility.7,21,23,41 The Critical Care Unit Leader role as it existed in the Hospital Emergency Incident Command System was eliminated under the new Hospital Incident Command System (HICS), but Hurricane Sandy highlighted the difficulty in attaining situational awareness without this position. ${ }^{15,31} \mathrm{~A}$ Critical Care Unit Leader, with authority and communication links equivalent to an Inpatient Unit Leader, is an 
essential direct point of contact for the Hospital Incident Command Center during evacuation of critically ill patients (see the "Surge Capacity Principles" article by Hick et $\mathrm{al}^{42}$ in this consensus statement). We have proposed using the nomenclature "critical care team leader" to specifically designate this emergency role with standardized responsibilities (e-Appendix 3). As a leader of one unified critical care evacuation team caring for patients distributed among many different units, we prefer using the description of team leader to avoid confusion. The CCTL should receive education and training similar to other HICS leaders. Critical care patients should be categorized (Fig 2) and iteratively reevaluated and recategorized, when applicable, by critical care resource, transport skill set, and transport type. ${ }^{43}$ Of note, certain patients may be so subspecialized (eg, a patient receiving centrally cannulated venoarterial extracorporeal membrane oxygenation [ECMO]), complicated, or severely critically ill that direct communication between the CCTL and Incident Command and regional specialty experts may be necessary to determine the best clinical evacuation and disposition. Evacuation drills should test the communication structure among the CCTL, HICS, and local or regional emergency operations center (EOC).

\section{Initiate Pre-Event ICU Evacuation Plan}

5a. If pre-event hospital evacuation of critically ill patients might be required, then we suggest planning for patient evacuation or shelter in place using an Incident Command System should begin as early as possible. Possible strategies include shelter in place, partial evacuation, or early evacuation, depending on the circumstances.

Some disasters, such as hurricanes, provide advance warning and, hence, permit a pre-event evacuation that can be planned and executed before the disaster occurs. Reports of actual hospital pre-event evacuations ${ }^{17,44}$ and the Hospital Evacuation Decision Guide published by the Agency for Healthcare Research and Quality ${ }^{41}$ are available to help hospitals to plan these movements. An Incident Command System structure should be activated and evaluate existing hospital resources, including food, water, backup generators, staff, and equipment. If power has been lost but the decision has not yet been made to evacuate, such as occurred in some hospitals during Hurricane Sandy, ${ }^{15}$ we suggest a checklist approach to ensure adequate ICU resources (see e-Appendix 4 for the Power Outage Checklist created by
1) ICU Resource Requirement:

a Non-Invasive Mechanical Ventilation (BIPAP/CPAP)

Mechanical Ventilator

- High Ventilator requirements (PEEP> 10 and $\mathrm{fiO} 2>60 \%$; or $\mathrm{PIP}>60$ )

a High-Frequency Oscillator

- Vasopressor, stable

Vasopressor, unstable (requiring titration or high dose)

Continuous renal replacement therapy (CRRT)

- Intracranial pressure monitor or drain (Bolt or EVD)

- Extracorporeal Membrane Oxygenation (ECMO)

- LVAD or Intra-aortic Balloon Pump (IABP)

- High risk upper airway

a Chest tube

Other unique ICU resource:

2) Transport Skill Requirement:

- Endotracheal Intubation

Central venous/arterial access placement

- Chest tube placement

r Routine ventilator management

- Non-invasive mechanical ventilation management

ARDS ventilator management

- Oscillator management

a Cardiac ICU

- Neuro ICU

Neonatal ICU

a Pediatric ICU

Morbid Obesity

C Continuous Dialysis (CRRT)

ㄷMO

Other transport skill:

3) Transport Type:
B BLS
ALS
Critical Care
Neonatal
Pediatric
Other (describe):

Figure 2 - Example of a Critical Care Patient Categorization Checklist. We suggest that every ICU routinely categorize every ICU patient by (1) ICU resource requirement, (2) transport skill requirement, and (3) transport type. Ideally, this ICU patient categorization would occur at least daily during routine care and be entered into an electronic checklist, such as a whiteboard or portable computer device (with a backup paper checklist). During a threatened or actual ICU evacuation, every ICU would categorize its patients more frequently, even hourly. Categorization should be performed by each unit leader most aware of patient details (ie, ICU attending physician or ICU charge registered nurse) and then relayed directly to and verified by the Critical Care Team Leader. Additionally, there should be a mechanism for electronically collating these data so that both the Critical Care Team Leader and the Incident Command can have real-time ICU situational awareness. $A L S=$ advanced life support $B I P A P=$ bilevel pressure ventilation; $B L S=$ basic life support; CRRT = continuous renal replacement therapy; ECMO = extracorporeal membrane oxygenation; $E V D=$ external ventricular drain; $L V A D=$ left ventricular assist device; $P E E P=$ positive end-expiratory pressure.

the NYU Langone Department of Pediatrics following its Hurricane Sandy experience).

The CCTL should start evacuation planning well in advance of the official decision to evacuate, starting by requesting that each ICU team complete the Critical Care Patient Categorization Checklist. Other responsibilities include identifying potential receiving hospitals for critically ill patients and facilitating and coordinating pre-event evacuation, if required. In some situations, the 
decision about whether to evacuate is clear, but in other situations, multiple factors must be considered. ${ }^{45}$ Similar to the power outage scenario, we also suggest a checklist approach to ICU evacuation when an ICU evacuation appears imminent (see e-Appendix 5 for the Evacuation Checklist also created by the NYU Langone Department of Pediatrics following Hurricane Sandy).

5b. We suggest Hospital Incident Command during a threatened hospital evacuation should have a clear and direct mechanism for communication with local governing bodies that control the timing and issuance of regional evacuation orders. To prevent obstruction of ground medical transport during hospital evacuation, coordination with local government regarding timing of recommendations for evacuation of the general population may be required. Efficient ground medical transport of patients during a hospital evacuation may be facilitated by providing a time period for hospital evacuation prior to recommendations for evacuation of the general population.

Ground transportation difficulties during hospital evacuation may occur during a natural disaster because of gridlock caused by evacuation of the general public. ${ }^{12,17}$ Air evacuation, therefore, is sometimes necessary. ${ }^{17}$ Coordination of hospital evacuation with local government orders for mandatory evacuation of the general public might mitigate transportation problems for ground ambulances. The need for transport resources can also be optimized by pre-event disaster planning, ${ }^{15}$ triage and discharge of patients who do not require further hospitalization, ${ }^{46,47}$ use of alternative ground transport modes in addition to medically configured vehicles, ${ }^{3,14}$ and transporting similar acuity patients in groups. $^{44}$

\section{Requesting Assistance for Evacuation}

6a. We suggest during a disaster or pandemic that overwhelms local and regional resources and requires large-scale hospital evacuations assistance, from national and/or international government medical support and evacuation agencies should be requested.

6b. We suggest the CCTL should be aware of the process for requesting evacuation assistance and the resources available at a regional and national level.

In the United States, the federal government mobilizes emergency medical resources through the National Disaster Medical System (NDMS). ${ }^{48-50}$ The hospital must request assistance through local emergency management, which triggers a chain of requests for regional, state, and federal assistance through the Federal Emergency Management Agency (e-Appendixes 6, 7). Since its inception in 1984, the first NDMS response requiring large-scale regional patient evacuation followed Hurricane Katrina in 2005. Lessons learned from that and other experiences contributed to continuous process improvements evident in the responses to Hurricanes Gustav and Ike in 2008 and the Haiti earthquake in 2010.

If federal aeromedical evacuation is required, the Federal Emergency Management Agency requests Department of Defense assistance for the Department of Health and Human Services-led evacuation. The US Transportation Command is the Department of Defense headquarters responsible for patient movement worldwide. ${ }^{51}$ The US Transportation Command will direct the patient to a properly staffed and equipped aeromedical team. Many very complex patients, though, cannot be moved en masse through this system. Hospitals should prioritize private rotor and fixed wing aircraft and critical care ground units for neonates and small pediatric patients as well as larger children or adults with very complicated management requirements. Nonspecialized and nonseverely critically ill patients should be designated for US federal evacuation.

The system in the United States is just one example of a federal evacuation system that could be adapted by other countries. e-Appendix 8 describes the coordination of international disaster emergency medical responses.

Ensure Adequate Power and Transport Ventilation Equipment

7a. We suggest surge ventilators with flexible electrical power and oxygen requirements should be available to support patients with respiratory failure that can maintain function while either (1) sheltering in place or (2) evacuating to an outside facility. These ventilators should be portable, run on alternating current power with battery backup, and have the ability to run on low-flow oxygen without a highpressure gas source. Surge ventilators may be of limited capability but should be able to ventilate and oxygenate patients with acute lung injury or ARDS as well as airflow obstruction. This requires capability to deliver a high minute ventilation, high flow, and high positive end-expiratory pressure. They should be safe (disconnect alarm) and relatively easy for staff to operate. 
7b. We suggest availability of adequate portable energy and medical gas flexible ventilators that can provide accurate small tidal volumes or pressure limits for the premature and neonatal patients expected at designated hospitals (for instance pediatric centers or hospitals with a neonatal ICU). Special consideration should be given to creating a standard, quickly accessible regional stockpile of mechanical ventilators for evacuation of neonatal patients as it may not be feasible for some nonpediatric centers to have adequate numbers of portable energy and gas flexible neonatal ventilators.

Available transport-type ventilators for evacuation of patients with respiratory failure may come from local, regional, or national resources. Although functional transport-type ventilators capable of operating on battery power and with low-flow oxygen are optimal during hospital evacuation in a disaster situation, ${ }^{52,53}$ bag valve ventilation is readily available and has been used over days to support patients, including neonates, ${ }^{54}$ during prolonged hospital evacuations or when electrical power is lost or a compressed gas source is not available. ${ }^{23}$ Disadvantages to bag valve ventilation of intubated patients, however, are numerous and include requirement of a health-care worker to provide assisted ventilations, health-care worker fatigue during provision of assisted ventilations, inefficient use of oxygen resources, inadequate support of ventilation and oxygenation for patients with severe acute lung injury, and patient harm (barotrauma, pneumothorax, respiratory alkalosis, and accidental extubation). ${ }^{55}$

\section{Prioritizing Critical Care Patients for Evacuation}

8. We suggest evacuation order and identification of appropriate facility should be based on the following factors:

8a. In a time-limited evacuation, less critical patients can be evacuated faster and with fewer resources per patient and, thus, may be moved first in order to evacuate the most patients in the fastest time.

$8 b$. When there is adequate time for evacuation, then more critically ill patients may be moved first and in parallel with less ill patients. Similar acuity patients often use similar transport resources and strain the same group of sending staff members. Thus, moving both the less critical and more critical patients simultaneously in parallel, as compared with sequentially in series (when there is adequate time to evacuate the entire hospital), may decrease the overall time to evacuation.

8c. In some situations, moving groups of similar-type patients to a single hospital entity may enable the sending hospital to provide staff to a single location to facilitate continuity of care and allow receiving hospitals to preplan to surge for specific types of patients and cluster disaster resources.

8d. The most critically ill patients dependent on mechanical devices for life support may, in some conditions, be safely cared for with a shelter-in-place strategy if it is deemed the risk of evacuation is too high.

Priorities for evacuating patients are situation dependent. This includes priorities for which patients are evacuated first or last or which patients are sheltered in place.

In some situations, it may be favorable to evacuate less ill patients first, and in other situations, it may be favorable to evacuate the most critically ill patients first. The receiving facility should be capable of providing care for the specific problems of patients. Selection of a receiving facility may be done with one-to-one matching of a patient with a receiving facility, but in some situations, patients may be grouped for transport to a receiving facility.

The CCTL at the transferring hospital must assess the clinical condition and ongoing care requirements of critically ill patients and with local or regional Incident Command, assess the capabilities of the hospital to continue caring for these patients. Factors to consider are infrastructure damage, medical supplies and staff resources, anticipated additional patients and their needs, and provider capability. Based on this assessment, the EOC leadership must work closely with transportation experts and available regional critical care units to match patient care needs to resources and services while minimizing transport distances and using all existing modes of transportation. In general, it is more common to move critically ill patients first, ${ }^{3,21,56}$ and consideration should be given to moving groups of patients of a specific specialty type together in certain situations. ${ }^{44}$

If the disaster-affected hospital is able to deliver care, it should provide medical supplies and assistance to rapidly stabilize and prepare patients for evacuation while EOC personnel are identifying transfer locations. ${ }^{5}$ For instance, burn surgeons and staff have been deployed to the incident hospital to ensure adequate patient resuscitation and management prior to evacuation for definitive burn care. ${ }^{36,57}$ In these situations, moving patients 
with both more critical and less critical illness in parallel after initial stabilization may shorten overall evacuation time. When the risk of transport is deemed equal to or greater than the risk of caring for a critically ill patient in the disaster area, the patient may be cared for in place.

\section{Critical Care Patient Distribution}

9a. We suggest during isolated, small, or pre-event ICU evacuations, CCTLs should coordinate with Hospital Incident Command and identify receiving hospitals for patient evacuation via the usual practice of provider-to-provider communication.

9b. We suggest during multiple-facility, large, or late ICU evacuations, the usual provider-to-provider system of communication for identification of receiving facilities should be augmented by other Regional or National Incident Management Systems.

9b.i. Every hospital should be specifically affiliated with (and drill evacuation with) a Regional or National Command Center for such events. Regional or National Command Centers may need to assume responsibility for designation of the receiving facilities for their patients.

9b.ii. We suggest when a Regional or National Emergency Command Center assumes responsibility for patient distribution, they should be responsible for identifying receiving facilities that match ICU patient resource requirements.

9b.iii. We suggest the Regional or National Emergency Command Center should enlist assistance of regional specialist experts to assist in the above matching process for distribution of patients requiring highly specialized care among receiving centers.

$9 c$. We suggest assignment of transportation resources and lines of critical care patient evacuation should follow common existing referral patterns provided receiving facilities retain adequate capacity to care for these patients.

9d. We suggest patients who require advanced specialty care should be directed to high-volume centers and distribution take into account the capacity and resources required to provide ongoing care to these patients.

Hospital evacuations during disasters in the United States often have been coordinated through existing referral patterns using referring physician-to-receiving physician communication. . $17,21,44,58,59$ However, this system may be overwhelmed. When this occurs, regional or national agencies are responsible for selecting appropriate receiving hospitals for evacuations. The responsible agencies vary from country to country. For instance, in the United Kingdom, emergency evacuation and patient allocation during a disaster is the responsibility of the National Health Service. In the United States, an individual state government must request the NDMS to provide assistance with patient evacuation from hospitals. ${ }^{16,56}$ Even when these resources are deployed to assist with hospital evacuation, however, the CCTL at the referring facility may still be required to identify critically ill patients with life-support needs that may require specialty teams for transport, such as for patients with ARDS supported on mechanical ventilation or ECMO. ${ }^{35,38,60-65}$

\section{Preparing the Critical Care Patient for Evacuation}

10a. We suggest standardized preparation of critically ill patients should be performed prior to hospital-tohospital transfer, including initial stabilization, diagnostic procedures, damage control procedures, and medical interventions to address anticipated physiologic changes during transport.

A systematic approach to the decision to evacuate and prepare the patient for the physiologic stresses of transport will minimize the chance of complications in civilian, ${ }^{66}$ military, ${ }^{61}$ and neonatal critical care transport. ${ }^{40}$ The oversight of this process should be performed by the CCTL at the sending hospital because this individual is best qualified to determine the appropriateness of transfer for patients.

$10 \mathrm{~b}$. We suggest the transport team should provide the equipment used for transport to ensure compatibility and familiarity during transport and retain important resources at the source institution for ongoing care of the remaining patients.

A risk of medical equipment malfunction exists during transport due to such factors as temperature and barometric pressure swings, vibration, limited supply of electric power and oxygen, and electromagnetic interference. A solution adopted by experienced military transport programs is to equip the transport team with a standard gear set. ${ }^{61,67}$ The transport team's equipment is applied to patients in the sending hospital, and patients are observed for stability prior to departure.

10c. We suggest evacuation planning and coordination should include the provision of additional expert providers, staff, and equipment to assist in the ongoing provision of care in situations where patient 
volume, acuity, or nature of illness or injury exceeds the capabilities of the CCTL and staff.

A solution to relieve caregivers in a disaster area and improve continuity of care is to insert teams that can manage these patients until they are ready for transport. This is most pertinent for highly specialized care not typically provided at the sending facility. This model has been successfully used in disasters that produced casualties requiring burn care ${ }^{68}$ or ECMO. ${ }^{35}$

10d. We suggest utilizing a staging area for patients prepared and awaiting transport. This area should ideally be located near the point of embarkation and be staffed by medical personnel with training and experience in critical care evacuation. These personnel should be prepared to provide triage and perform ongoing medical care interventions prior to transport. The area should have the capability for additional surgical and medical stabilization pretransport if necessary.

One of the challenges of coordination of a multicasualty evacuation is managing the time between availability of the evacuation vehicle and the readiness of patients for transport. This is best handled by setting up a staging area staffed by medical personnel who are experienced in preparing critically ill patients for evacuation. ${ }^{69}$ This team must be trained and equipped to address the need for issues such as central venous access, endotracheal intubation, pneumothorax decompression, and pain management. ${ }^{69}$ This approach to staging patients is standard for multicasualty evacuation performed by the US Air Force and was successfully used by the Australian Air Force following a terrorist bombing in Bali, Indonesia. ${ }^{70}$

When possible, the most critical patients should be staged directly from their bed in the sending hospital. This can be accomplished by adding a transport staging team to the hospital. Staging patients in place will minimize handoffs and decrease their exposure to the transport environment. However, in some circumstances, it is necessary to create a staging area adjacent to an airfield that will serve as a point of embarkation. This may be required if there is a long distance from hospital to airfield, there are limited resources to transport patients from the bedside, or the staging area is collecting patients from multiple hospitals for evacuation on the same vehicle.

\section{Sending Critical Care Patient Information With Patient}

11a. We suggest electronic transfer of patient information to the receiving hospital is optimal because a complete medical record can be included. Electronic transfer may be through an intranet or by copying patient information onto a USB flash memory drive or compact disk and transferring the information with the patient ( see the "Business and Continuity of Operations" article by Tosh et al $^{71}$ in this guideline).

$11 b$. We suggest a paper medical record be required to travel with the patient because there may be no ability to send an electronic copy of the medical record, or the receiving facility may not be able to read the electronic format of the medical record. A backup paper system may require (a) a printed copy of the electronic medical record or (b) a handwritten patient identification on a standardized patient tracking form. Any paper system should include basic patient identification, problem lists, and medications on forms that travel with the patient.

The number and rapidity of patient transfers that occur during a disaster places the patients at risk for medical errors. This risk can be mitigated by complete transfer of the patient's medical record. ${ }^{44}$ Electronic media provide the most efficient means of transferring a large volume of data; however, effective electronic transfer may be limited by incompatibility issues between sending and receiving hospitals or because of computer system malfunction. ${ }^{21}$ For this reason, it is important to have a paper backup copy of the most essential patient information for transfer. The most critical data to prevent patient complications can be efficiently conveyed with compact records, such as the HICS forms, or even by writing on patient dressings. ${ }^{70}$

\section{Transporting Critical Care Patients to Receiving Hospitals}

12a. We suggest transportation methods should prioritize moving the greatest number of patients as rapidly and safely as possible to locations with adequate capacity and expertise where definitive care can be provided.

Rapid decompression of the disaster area provides patients with access to more advanced care and makes resources in the disaster available for additional patients.

12b. We suggest local evacuation of highest acuity patients to hospitals with additional capacity by ground or rotary transport may be most appropriate to minimize risk and reduce ongoing critical care demands at the incident facility.

If high acuity patients overwhelm the incident hospital, the most rapid means of decompression is to transfer 
patients to the nearest hospital with adequate resources. This leverages existing transport teams and referral patterns. A successful model of this strategy is illustrated in a report of the response to a casualty-producing tornado. ${ }^{6}$ Importantly, this patient distribution needs to be done in conjunction with the hospital's Health Care Coalition or Regional Health Authority to ensure appropriate situational awareness.

12c. We suggest alteration in the usual standards for modes of transport may be required during a disaster where transport resources are overwhelmed and evacuation and transport of critically ill patients to a receiving hospital ICU is required.

The usual standards for patient transport may not be achievable in a disaster. In this situation, vehicles that are not equipped for critical care transport, such as buses, trucks, and passenger cars, ${ }^{28}$ or nonmedically configured helicopters ${ }^{3}$ may need to be used. Alternatively, if a disaster renders roads impassable, it may be necessary to perform helicopter transports for patients who would otherwise be well managed with a ground ambulance.

\section{Tracking Critical Care Patients and Equipment}

13a. We suggest tracking of patients should commence in the sending clinical unit; continue to the point of embarkation; and, if possible, continue to the destination facility. Tracking of the patient and equipment should commence prior to being loaded onto the transportation. Minimum data sets for tracking should include the patient first and last name, date of birth, medical record number or tracking number or triage number, time leaving facility, transportation company name and transport vehicle number, and expected destination and next of kin.

13b. We suggest both the evacuating and receiving hospitals should track patients and equipment.

In addition to clinical implications for tracking patients' whereabouts, it is equally compelling for family and friends to know where their loved ones are being sent. An efficient mechanism is necessary to track patients from the point of initial triage back through the evacuation chain to the final receiving hospital. This has been traditionally managed with casualty cards, but several robust electronic systems have been developed and demonstrated to be effective. ${ }^{72,73}$ The US Air Force Aeromedical Evacuation System has developed a web-based approach to provide in-transit visibility that has proven reliable in tracking tens of thousands of casualties from the recent wars in Iraq and Afghanistan. ${ }^{51}$ The availability of patient care equipment must also be closely tracked. The same system that tracks casualty movement can also be extended to include equipment tracking.

13c. We suggest tracking systems may be electronic or paper. In the event of complete power failure, however, a redundant paper system for tracking of patients and equipment should be performed by both sending and receiving hospitals, with communications provided to the sending hospital and/or a centralized coordinating center to confirm receipt of the patients.

13d. We suggest evacuation drills should test tracking of patients and equipment both by electronic and paper systems.

Electronic tracking systems have performed well in disasters and may be more efficient than paper-based systems. ${ }^{74,75}$ However, disaster conditions may cause failure of an electronic system, so disaster medical personnel must be prepared to deploy a paper or other manual system. ${ }^{76} \mathrm{~A}$ large-scale exercise provides an opportunity to identify weaknesses and to train personnel to optimally use the system. ${ }^{44}$ Multiple models have been published describing successful evaluation of a tracking system.77-81

\section{Areas for Research}

The published literature on evacuation of critically ill patients is extensive, but the level of evidence and generalizability of these case reports or single-institution experiences are limited. The diversity of health-care systems and their surrounding regional resources, along with the variation and complexity associated with the care and transport of critically ill patients following a variety of disaster events, makes it impossible to provide a series of systematic, evidence-based recommendations to guide universal preparations in this area. Future reports should make every effort to organize experience using a current, standardized organizational framework offered by HICS and similar international guidelines to facilitate synthesis of the information they provide and advancement and integration of the body of knowledge in this important and challenging area.

All critical care providers should become familiar with the newly proposed ICU Evacuation Timeline and its three stages: (1) no immediate threat, (2) ICU evacuation threat, and (3) ICU evacuation. We have made several recommendations that dramatically increase, standardize, and codify the role of the ICU physician 
leader during ICU evacuation in the role of the CCTL. We have proposed two standard tools, including the CCTL Responsibilities and Critical Care Patient Categorization Checklist. We have also presented three example tools, including (1) the Power Outage Checklist and (2) the Evacuation Checklist (both from the NYU Langone Department of Pediatrics) and (3) a vertical evacuation simulation scenario. These first attempts are meant to spur creation of more finished documents adapted to one's own facility and improved on for future directions. Finally, policy efforts must be made to enable regional patient information sharing both in real time during disasters to enable effective regional critical care evacuation and in postdisasters for event analysis to improve regional and hospital critical care evacuation processes.

\section{Conclusions}

Successful ICU evacuation during a disaster requires active preparation, participation, communication, and leadership by critical care providers. All critical care providers have a professional obligation to become better trained, prepared, and engaged with the process of ICU evacuation to provide a safe continuum of critical care during a disaster.

\section{Acknowledgments}

Author contributions: M. A. K. had full access to all of the data in the study and takes responsibility for the integrity of the data and the accuracy of the data analysis. M. A. K., A. S. N., W. B., R. F., S. E., L. R., N. K., A. V. D., M. D. C., and C. K. G. contributed to the development of PICO questions; M. A. K., A. S. N., W. B., R. F., S. E., L. R., and C. K. G. conducted the literature review; M. A. K., A. S. N., W. B., R. F., S. E., L. R., and C. K. G. contributed to development of expert opinion suggestion; M. A. K., A. S. N., W. B., R. F., S. E., L. R., N. K., A. V. D., M. D. C., and C. K. G. contributed to the conception and design, or acquisition of data, or analysis and interpretation of data from the Delphi process; M. A. K., A. S. N., W. B., R. F., S. E., L. R., and C. K. G. developed and drafted the manuscript; and N. K., A. V. D., and M. D. C. revised the manuscript critically for important intellectual content.

Financial/nonfinancial disclosures: The authors have reported to CHEST the following conflicts: Dr Einav received grant money, royalties, and research funds for topics unrelated to this manuscript. Dr Rubinson received grant money for two unrelated National Institutes of Health sponsored studies and makes public statements related to this topic. Dr Grissom receives grant support from the NIH, National Heart Lung and Blood Institute as the principal investigator for the Utah Center in the prevention and early treatment of acute lung injury. The remaining authors have reported that no potential conflicts of interest exist with any companies/organizations whose products or services may be discussed in this article.

Endorsements: This consensus statement is endorsed by the American Association of Critical-Care Nurses, American Association for Respiratory Care, American College of Surgeons Committee on Trauma, International Society of Nephrology, Society for Academic Emergency Medicine, Society of Critical Care Medicine, Society of Hospital Medicine, World Federation of Pediatric Intensive and Critical Care Societies, World Federation of Societies of Intensive and Critical Care Medicine.

Role of sponsors: The American College of Chest Physicians was solely responsible for the development of these guidelines. The remaining supporters played no role in the development process.
External supporting organizations cannot recommend panelists or topics, nor are they allowed prepublication access to the manuscripts and recommendations. Further details on the Conflict of Interest Policy are available online at http://chestnet.org.

Other contributions: The authors thank librarian Alicia Livinski, $\mathrm{MA}, \mathrm{MPH}$, for assistance in the preparation of the evidence base for this article and Scott Aronson of Russell Phillips \& Associates, LLC, for evacuation expertise and contributions in generating research questions. The views expressed in this consensus statement are those of the author (A. S. N.) and do not reflect the official policy or position of the Department of the Army, Department of Defense, or the US Government. The opinions expressed within this manuscript are solely those of the author (M. D. C.) and do not represent the official position or policy of the Royal Canadian Medical Service, Canadian Armed Forces, or the Department of National Defence.

Additional information: The e-Appendixes can be found in the Supplemental Materials section of the online article.

Collaborators: Executive Committee: Michael D. Christian, MD, FRCPC, FCCP; Asha V. Devereaux, MD, MPH, FCCP, co-chair; Jeffrey R. Dichter, MD, co-chair; Niranjan Kissoon, MBBS, FRCPC; Lewis Rubinson, MD, PhD; Panelists: Dennis Amundson, DO, FCCP; Michael R. Anderson, MD; Robert Balk, MD, FCCP; Wanda D. Barfield, MD, MPH; Martha Bartz, MSN, RN, CCRN; Josh Benditt, MD; William Beninati, MD; Kenneth A. Berkowitz, MD, FCCP; Lee Daugherty Biddison, MD, MPH; Dana Braner, MD; Richard D Branson, MSc, RRT; Frederick M. Burkle Jr, MD, MPH, DTM; Bruce A. Cairns, MD; Brendan G. Carr, MD; Brooke Courtney, JD, MPH; Lisa D. DeDecker, RN, MS; COL Marla J. De Jong, PhD, RN [USAF]; Guillermo Dominguez-Cherit, MD; David Dries, MD; Sharon Einav, MD; Brian L. Erstad, PharmD; Mill Etienne, MD; Daniel B. Fagbuyi, MD; Ray Fang, MD; Henry Feldman, MD; Hernando Garzon, MD; James Geiling, MD, MPH, FCCP; Charles D. Gomersall, MBBS; Colin K. Grissom, MD, FCCP; Dan Hanfling, MD; John L. Hick, MD; James G. Hodge Jr, JD, LLM; Nathaniel Hupert, MD; David Ingbar, MD, FCCP; Robert K. Kanter, MD; Mary A. King, MD, MPH, FCCP; Robert N. Kuhnley, RRT; James Lawler, MD; Sharon Leung, MD; Deborah A. Levy, PhD, MPH; Matthew L. Lim, MD; Alicia Livinski, MA, MPH; Valerie Luyckx, MD; David Marcozzi, MD; Justine Medina, RN, MS; David A. Miramontes, MD; Ryan Mutter, PhD; Alexander S. Niven, MD, FCCP; Matthew S. Penn, JD, MLIS; Paul E. Pepe, MD, MPH; Tia Powell, MD; David Prezant, MD, FCCP; Mary Jane Reed, MD, FCCP; Preston Rich, MD; Dario Rodriquez, Jr, MSc, RRT; Beth E. Roxland, JD, MBioethics; Babak Sarani, MD; Umair A. Shah, MD, MPH; Peter Skippen, MBBS; Charles L. Sprung, MD; Italo Subbarao, DO, MBA; Daniel Talmor, MD; Eric S. Toner, MD; Pritish K. Tosh, MD; Jeffrey S. Upperman, MD; Timothy M. Uyeki, MD, MPH, MPP; Leonard J. Weireter Jr, MD; T. Eoin West, MD, MPH, FCCP; John Wilgis, RRT, MBA; ACCP Staff: Joe Ornelas, MS; Deborah McBride; David Reid; Content Experts: Amado Baez, MD; Marie Baldisseri, MD; James S. Blumenstock, MA; Art Cooper, MD; Tim Ellender, MD; Clare Helminiak, MD, MPH; Edgar Jimenez, MD; Steve Krug, MD; Joe Lamana, MD; Henry Masur, MD; L. Rudo Mathivha, MBChB; Michael T. Osterholm, PhD, MPH; H. Neal Reynolds, MD; Christian Sandrock, MD, FCCP; Armand Sprecher, MD, MPH; Andrew Tillyard, MD; Douglas White, MD; Robert Wise, MD; Kevin Yeskey, MD.

\section{References}

1. Ornelas J, Dichter JR, Devereaux AV, Kissoon N, Livinski A, Christian MD; on behalf of the Task Force for Mass Critical Care. Methodology: care of the critically ill and injured during pandemics and disasters: CHEST consensus statement. Chest. 2014; 146(4_suppl):35S-41S.

2. Daugherty EL, Rubinson L. Preparing your intensive care unit to respond in crisis: considerations for critical care clinicians. Crit Care Med. 2011;39(11):2534-2539.

3. Schultz CH, Koenig KL, Lewis RJ. Implications of hospital evacuation after the Northridge, California, earthquake. $N$ Engl J Med. 2003;348(14):1349-1355.

4. Iwashyna TJ, Christie JD, Moody J, Kahn JM, Asch DA. The structure of critical care transfer networks. Med Care. 2009;47(7):787-793. 
5. Lavon O, Hershko D, Barenboim E. Large-scale air-medical transport from a peripheral hospital to level-1 trauma centers after remote mass-casualty incidents in Israel. Prehosp Disaster Med. 2009;24(6):549-555.

6. Carlascio DR, McSharry MC, LeJeune CJ, Lewis JH, Schneider CN, Marshall WJ. Air medical response to the 1990 Will County, Illinois, tornado. J Air Med Transp. 1991;10(10):7,9-11,13-16.

7. Fuzak JK, Elkon BD, Hampers LC, et al. Mass transfer of pediatric tertiary care hospital inpatients to a new location in under 12 hours: lessons learned and implications for disaster preparedness. J Pediatr. 2010;157(1):138-143.

8. Cryer HG, Hiatt JR, Eckstein M, et al. Improved trauma system multicasualty incident response: comparison of two train crash disasters. J Trauma. 2010;68(4):783-789.

9. Kanter RK. Regional variation in critical care evacuation needs for children after a mass casualty incident. Disaster Med Public Health Prep. 2012;6(2):146-149.

10. Yurt RW, Lazar EJ, Leahy NE, et al. Burn disaster response planning an urban region's approach. J Burn Care Res. 2008;29(1):158-165.

11. Stamell EF, Foltin GL, Nadler EP. Lessons learned for pediatric disaster preparedness from September 11, 2001: New York City trauma centers. J Trauma. 2009;67(suppl):S84-S87.

12. Gray BH, Hebert K. Hospitals in Hurricane Katrina: challenges facing custodial institutions in a disaster. J Health Care Poor Underserved. 2007;18(2):283-298.

13. Orlando S, Bernard ML, Mathews P. Neonatal nursing care issues following a natural disaster: lessons learned from the Katrina experience. J Perinat Neonatal Nurs. 2008;22(2):147-153.

14. Koyama A, Fuse A, Hagiwara J, et al. Medical relief activities, medical resourcing, and inpatient evacuation conducted by Nippon Medical School due to the Fukushima Daiichi Nuclear Power Plant accident following the Great East Japan Earthquake 2011. J Nippon Med Sch. 2011;78(6):393-396

15. Powell T, Hanfling D, Gostin LO. Emergency preparedness and public health: the lessons of Hurricane Sandy. JAMA. 2012;308(24): 2569-2570.

16. Farmer JC, Carlton PK Jr. Providing critical care during a disaster: the interface between disaster response agencies and hospitals. Crit Care Med. 2006;34(suppl):S56-S59.

17. Sexton KH, Alperin LM, Stobo JD. Lessons from Hurricane Rita: the University of Texas Medical Branch Hospital's evacuation. Acad Med. 2007;82(8):792-796.

18. Mason WL. The incomplete circle of the National Disaster Medical System: what Arkansas hospitals learned from hurricane Gustav. Biosecur Bioterror. 2010;8(2):183-191.

19. Sternberg E, Lee GC, Huard D. Counting crises: US hospital evacuations, 1971-1999. Prehosp Disaster Med. 2004;19(2):150-157.

20. Murphy GR, Foot C. ICU fire evacuation preparedness in London: a cross-sectional study. Br J Anaesth. 2011;106(5):695-698.

21. Uppal A, Evans L, Chitkara N, et al. In search of the silver lining: the impact of Superstorm Sandy on Bellevue Hospital. Ann Am Thorac Soc. 2013;10(2):135-142.

22. Taylor IL. Hurricane Katrina's impact on Tulane's teaching hospitals. Trans Am Clin Climatol Assoc. 2007;118:69-78.

23. deBoisblanc BP. Black Hawk, please come down: reflections on a hospital's struggle to survive in the wake of Hurricane Katrina. Am J Respir Crit Care Med. 2005;172(10):1239-1240.

24. Gildea JR, Etengoff S. Vertical evacuation simulation of critically ill patients in a hospital. Prehosp Disaster Med. 2005;20(4):243-248.

25. Iserson KV. Vertical hospital evacuations: a new method. South Med J. 2013;106(1):37-42.

26. Manion P, Golden IJ. Vertical evacuation drill of an intensive care unit: design, implementation, and evaluation. Disaster Manag Response. 2004;2(1):14-19.

27. King MA, Blayney C. Sample vertical evacuation simulation. Paper presented at: Northwest Healthcare Response Network, Pediatric Disaster Response Workshop; October 4, 2013; Renton, WA.

28. Tanaka H, Iwai A, Oda J, et al. Overview of evacuation and transport of patients following the 1995 Hanshin-Awaji earthquake. J Emerg Med. 1998;16(3):439-444.
29. Born CT, Briggs SM, Ciraulo DL, et al. Disasters and mass casualties: I. General principles of response and management. J Am Acad Orthop Surg. 2007;15(7):388-396.

30. Cybulski P. Evacuation of a critical care unit. Dynamics. 2003;14(3): 21-23.

31. California Emergency Medical Services Authority. Disaster Medical Services Division-Hospital Incident Command System Guidebook. Rancho Cordova, CA: California Emergency Medical Services Authority; 2006.

32. Gostin LO. International infectious disease law: revision of the World Health Organization's International Health Regulations. JAMA. 2004;291(21):2623-2627.

33. Franck L, Epstein B, Adams S. Disaster preparedness for the ICN evolution and testing of one unit's plan. Pediatr Nurs. 1993;19(2): 122-127.

34. Hon KL, Olsen H, Totapally B, Leung TF. Air versus ground transportation of artificially ventilated neonates: comparative differences in selected cardiopulmonary parameters. Pediatr Emerg Care. 2006;22(2):107-112.

35. Burns BJ, Habig K, Reid C, et al. Logistics and safety of extracorporeal membrane oxygenation in medical retrieval. Prehosp Emerg Care. 2011;15(2):246-253.

36. Mozingo DW, Barillo DJ, Holcomb JB. The Pope Air Force Base aircraft crash and burn disaster. I Burn Care Rehabil. 2005; 26(2):132-140

37. Kalisch BJ, Kalisch PA, Burns SM, Kocan MJ, Prendergast V. Intrahospital transport of neuro ICU patients. J Neurosci Nurs. 1995;27(2):69-77.

38. Noah MA, Peek GJ, Finney SJ, et al. Referral to an extracorporeal membrane oxygenation center and mortality among patients with severe 2009 influenza A(H1N1). JAMA. 2011;306(15): 1659-1668.

39. Farto e Abreu P, Thomas B, Loureiro J, Roquette J, Ferreira R. Interhospital transfer of critically-ill patients for urgent cardiac surgery after placement of an intra-aortic balloon pump. Rev Port Cardiol. 2002;21(10):1115-1123

40. Annibale DJ, Cahill JB, Tuttle DS, Williford WL, Wagner CL, Purohit D. Preparation of the critically ill neonate for transport. J S C Med Assoc. 2002;98(3):129-136.

41. Zane R, Biddinger P, Hassol A, Rich T, Gerber J, DeAngelis J. Hospital Evacuation Decision Guide. Rockville, MD: Agency for Healthcare Research and Quality, US Department of Health and Human Services; 2010.

42. Hick JL, Einav S, Hanfling D, et al; on behalf of the Task Force for Mass Critical Care. Surge capacity principles: care of the critically ill and injured during pandemics and disasters: CHEST consensus statement. Chest. 2014;146(4_suppl):e1S-e16S.

43. Bayard D. Haiti earthquake relief, phase two-long-term needs and local resources. N Engl J Med. 2010;362(20):1858-1861.

44. Verni C. A hospital system's response to a hurricane offers lessons, including the need for mandatory interfacility drills. Health Aff (Millwood). 2012;31(8):1814-1821.

45. Adini B, Laor D, Cohen R, Israeli A. Decision to evacuate a hospita during an emergency: the safe way or the leader's way? J Public Health Policy. 2012;33(2):257-268.

46. Zoraster RM, Amara R, Fruhwirth K. Transportation resource requirements for hospital evacuation. Am J Disaster Med. 2011;6(3) 173-186.

47. Sternberg E, Lee GC. New York City's healthcare transportation during a disaster: a preparedness framework for a wicked problem. Prehosp Disaster Med. 2009;24(2):95-107.

48. Franco C, Toner E, Waldhorn R, Inglesby TV, O’Toole T. The national disaster medical system: past, present, and suggestions for the future. Biosecur Bioterror. 2007;5(4):319-325.

49. Murray JS. National Disaster Medical System. Am J Nurs. 2012; 112(2):58-63.

50. Stopford BM. The National Disaster Medical System-America's medical readiness force. Disaster Manag Response. 2005;3(2):53-56.

51. Lezama NG, Riddles LM, Pollan WA, Profenna LC. Disaster aeromedical evacuation. Mil Med. 2011;176(10):1128-1132. 
52. Sprung CL, Kesecioglu J; European Society of Intensive Care Medicine's Task Force for intensive care unit triage during an influenza epidemic or mass disaster. Chapter 5. Essential equipment, pharmaceuticals and supplies. Recommendations and standard operating procedures for intensive care unit and hospital preparations for an influenza epidemic or mass disaster. Intensive Care Med. 2010;36(suppl 1):S38-S44.

53. Dickson RP, Hotchkin DL, Lamm WJ, et al. A porcine model for initial surge mechanical ventilator assessment and evaluation of two limited-function ventilators. Crit Care Med. 2011;39(3):527-532.

54. Barkemeyer BM. Practicing neonatology in a blackout: the University Hospital NICU in the midst of Hurricane Katrina: caring for children without power or water. Pediatrics. 2006;117(5 Pt 3):S369-S374.

55. Hanfling D, Altevogt BM, Viswanathan K, Gostin LO, eds; Committee on guidance for Establishing Crisis Standards of Care for Use in Disaster Situations; Board on Health Sciences Policy (HSP); Institute of Medicine (IOM). Crisis Standards of Care: A Systems Framework for Catastrophic Disaster Response (2012). Washington, DC: The National Academies Press; 2012.

56. Bagaria J, Heggie C, Abrahams J, Murray V. Evacuation and sheltering of hospitals in emergencies: a review of international experience. Prehosp Disaster Med. 2009;24(5):461-467.

57. Cancio LC, Horvath EE, Barillo DJ, et al. Burn support for Operation Iraqi Freedom and related operations, 2003 to 2004. J Burn Care Rehabil. 2005;26(2):151-161.

58. Bernard M, Mathews PR. Evacuation of a maternal-newborn area during Hurricane Katrina. MCN Am J Matern Child Nurs. 2008; 33(4):213-223.

59. Perrin K. A first for this century: closing and reopening of a children's hospital during a disaster. Pediatrics. 2006;117(5 pt 3):S381-S385.

60. Forrest P, Ratchford J, Burns B, et al. Retrieval of critically ill adults using extracorporeal membrane oxygenation: an Australian experience. Intensive Care Med. 2011;37(5):824-830.

61. Beninati W, Meyer MT, Carter TE. The critical care air transport program. Crit Care Med. 2008;36(suppl):S370-S376.

62. Kashani KB, Farmer JC. The support of severe respiratory failure beyond the hospital and during transportation. Curr Opin Crit Care. 2006;12(1):43-49.

63. Rice DH, Kotti G, Beninati W. Clinical review: critical care transport and austere critical care. Crit Care. 2008;12(2):207.

64. D'Ancona G, Capitanio G, Chiaramonte G, et al. Extracorporeal membrane oxygenator rescue and airborne transportation of patients with influenza A (H1N1) acute respiratory distress syndrome in a Mediterranean underserved area. Interact Cardiovasc Thorac Surg. 2011;12(6):935-937.

65. Davies A, Jones D, Baily M, et al; Australia and New Zealand Extracorporeal Membrane Oxygenation (ANZ ECMO) Influenza Investigators. Extracorporeal membrane oxygenation for 2009 influenza $\mathrm{A}(\mathrm{H} 1 \mathrm{~N} 1)$ acute respiratory distress syndrome. JAMA 2009;302(17):1888-1895.
66. Teichman PG, Donchin Y, Kot RJ. International aeromedical evacuation. N Engl J Med. 2007;356(3):262-270.

67. Barillo DJ, Renz E, Broger K, Moak B, Wright G, Holcomb JB. An emergency medical bag set for long-range aeromedical transportation. Am J Disaster Med. 2008;3(2):79-86.

68. Cancio LC. Airplane crash in Guam, August 6, 1997: the aeromedical evacuation response. J Burn Care Res. 2006;27(5):642-648.

69. Hurd WW, Montminy RJ, De Lorenzo RA, Burd LT, Goldman BS, Loftus TJ. Physician roles in aeromedical evacuation: current practices in USAF operations. Aviat Space Environ Med. 2006;77(6):631-638.

70. Read D, Ashford B. Surgical aspects of Operation Bali Assist: initial wound surgery on the tarmac and in flight. ANZ J Surg. 2004; 74(11):986-991.

71. Tosh PK, Feldman H, Christian MD, Devereaux AV, Kissoon N, Dichter JR; on behalf of the Task Force for Mass Critical Care. Business and continuity of operations: care of the critically ill and injured during pandemics and disasters: CHEST consensus statement. Chest. 2014;146(4_suppl):e103S-e117S.

72. Alm AM, Gao T, White DM. Pervasive patient tracking for mass casualty incident response. AMIA Annu Symp Proc. 2006:842.

73. Bouman JH, Schouwerwou RJ, Van der Eijk KJ, van Leusden AJ, Savelkoul TJ. Computerization of patient tracking and tracing during mass casualty incidents. Eur J Emerg Med. 2000;7(3): 211-216.

74. Callaway DW, Peabody CR, Hoffman A, et al. Disaster mobile health technology: lessons from Haiti. Prehosp Disaster Med. 2012; 27(2):148-152.

75. MacDonald RD, Farr B, Neill M, et al. An emergency medical services transfer authorization center in response to the Toronto severe acute respiratory syndrome outbreak. Prehosp Emerg Care. 2004;8(2):223-231.

76. Hoskins JD, Graham RF, Robinson DR, Lutz CC, Folio LR. Mass casualty tracking with air traffic control methodologies. J Am Coll Surg. 2009;208(6):1001-1008.

77. Blake N, Stevenson K. Reunification: keeping families together in crisis. J Trauma. 2009;67(suppl):S147-S151.

78. Buono CJ, Chan TC, Killeen J, et al. Comparison of the effectiveness of wireless electronic tracking devices versus traditional paper systems to track victims in a large scale disaster. AMIA Annu Symp Proc. 2007:886.

79. Demers G, Kahn C, Johansson P, et al. Secure scalable disaster electronic medical record and tracking system. Prehosp Disaster Med. 2013;28(5):498-501.

80. Hamilton J. An Internet-based bar code tracking system: coordination of confusion at mass casualty incidents. Disaster Manag Response. 2003;1(1):25-28.

81. Maltz J, C Ng T, Li D, et al. The Trauma Patient Tracking System: implementing a wireless monitoring infrastructure for emergency response. Conf Proc IEEE Eng Med Biol Soc. 2005;3:2441-2446. 